Development of a Performance-Based Industrial Energy Efficiency Indicator for Cement Manufacturing Plants

Decision and Information Sciences Division

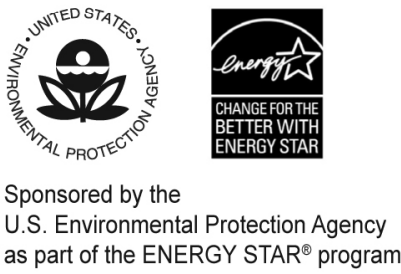




\section{About Argonne National Laboratory}

Argonne is a U.S. Department of Energy laboratory managed by The University of Chicago under contract W-31-109-Eng-38. The Laboratory's main facility is outside Chicago, at 9700 South Cass Avenue, Argonne, Illinois 60439. For information about Argonne, see www.anl.gov.

\section{Availability of This Report}

This report is available, at no cost, at http://www.osti.gov/bridge. It is also available on paper to the U.S. Department of Energy and its contractors, for a processing fee, from:

U.S. Department of Energy

Office of Scientific and Technical Information

P.O. Box 62

Oak Ridge, TN 37831-0062

phone (865) 576-8401

fax (865) 576-5728

reports@adonis.osti.gov

\section{Disclaimer}

This report was prepared as an account of work sponsored by an agency of the United States Government. Neither the United States Government nor any agency thereof, nor The University of Chicago, nor any of their employees or officers, makes any warranty, express or implied, or assumes any legal liability or responsibility for the accuracy, completeness, or usefulness of any information, apparatus, product, or process disclosed, or represents that its use would not infringe privately owned rights. Reference herein to any specific commercial product, process, or service by trade name, trademark, manufacturer, or otherwise, does not necessarily constitute or imply its endorsement, recommendation, or favoring by the United States Government or any agency thereof. The views and opinions of document authors expressed herein do not necessarily state or reflect those of the United States Government or any agency thereof, Argonne National Laboratory, or The University of Chicago. 


\section{Development of a Performance-Based Industrial Energy Efficiency Indicator for Cement Manufacturing Plants}

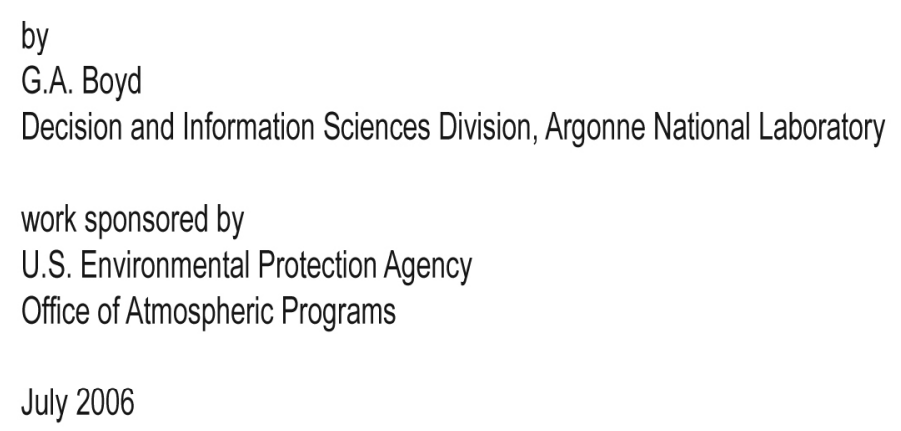





\section{CONTENTS}

ACKNOWLEDGMENTS ........................................................................

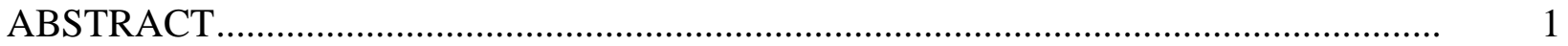

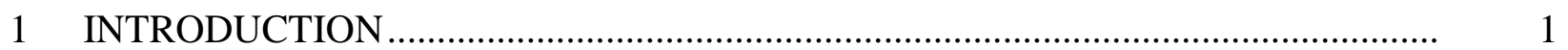

2 BENCHMARKING THE ENERGY EFFICIENCY OF INDUSTRIAL PLANTS ...... 3

2.1 Scope of an Indicator: Experience with the Cement Manufacturing Industry ...... 3

2.2 Data Sources ......................................................................................

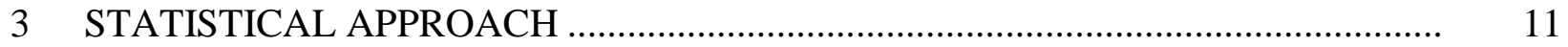

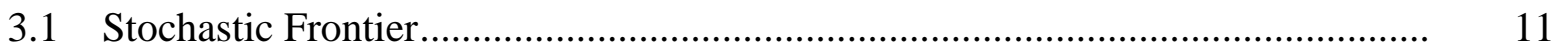

3.2 Evolution of the Model.............................................................................. 13

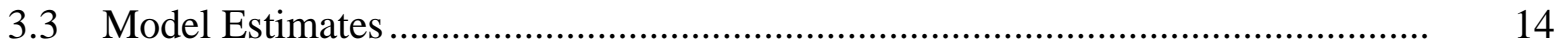

4 JUDGING THE ENERGY EFFICIENCY OF CEMENT

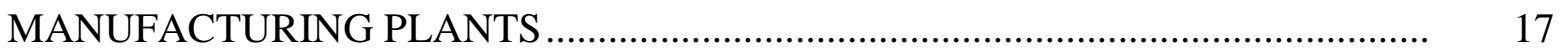

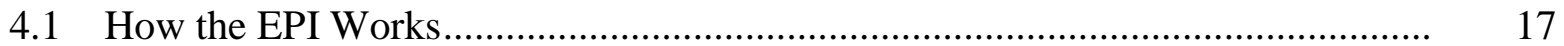

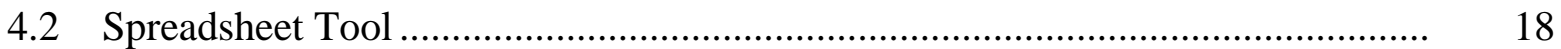

4.3 Use of the ENERGY STAR Cement EPI....................................................... 22

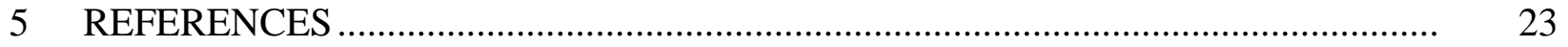

\section{FIGURES}

1 Kernel Density Plot of the Ratio of PCA to MECS Data for the Various Energy Sources

2 Input Section of the EPI Spreadsheet Tool ............................................................ 20

3 Output Section of the EPI Spreadsheet Tool .................................................... 21

4 Response of the EPI Score to a Change in the Definition of Capacity .......................... 22 


\section{TABLES}

1 Correlation Coefficient between PCA and MECS Plant-Level Energy Data................ 5

2 Sample Means for Selected Variables ................................................................... 10

3 Total Primary Energy Model Estimates........................................................... 16 


\section{ACKNOWLEDGMENTS}

This work was sponsored by the U.S. Environmental Protection Agency (EPA), Office of Atmospheric Programs. Portions of this report were presented at the Portland Cement Association's Joint Fall Meeting held on September 27-29, 2004, in Chicago, Illinois. The cooperation and support of the Portland Cement Association in providing critical data and analytic reviews are appreciated greatly. This research also benefited from comments by participants at the ENERGY STAR ${ }^{\circledR}$ Cement Industry Focus Meeting on May 5, 2004, in Washington, D.C., and Second Annual Focus Meeting on May 5, 2005, in Tucson, Arizona.

The research discussed in this report was conducted while the author was a U.S. Bureau of the Census (Census Bureau) research associate at the Chicago Census Research Data Center (RDC). The results and conclusions expressed herein are those of the author and do not necessarily indicate concurrence by the Census Bureau, Argonne National Laboratory, or the EPA. This report was screened to ensure that no confidential data are revealed. Support for this research at the Chicago Census RDC from the National Science Foundation (Awards SES0004335 and ITR-0427889) is gratefully acknowledged. 


\title{
DEVELOPMENT OF A PERFORMANCE-BASED INDUSTRIAL ENERGY EFFICIENCY INDICATOR FOR CEMENT MANUFACTURING PLANTS
}

\author{
by
}

\author{
G.A. Boyd
}

\begin{abstract}
Organizations that implement strategic energy management programs have the potential to achieve sustained energy savings if the programs are carried out properly. A key opportunity for achieving energy savings that plant managers can take is to determine an appropriate level of energy performance by comparing the plant's performance with that of similar plants in the same industry. Manufacturing plants can set energy efficiency targets by using performancebased indicators. The U.S. Environmental Protection Agency (EPA), through its ENERGY STAR ${ }^{\circledR}$ program, has been developing plant energy performance indicators (EPIs) to encourage a variety of U.S. industries to use energy more efficiently. This report describes work with the cement manufacturing industry to provide a plant-level indicator of energy efficiency for assembly plants that produce a variety of products, including Portland cement and other specialty cement products, in the United States. Consideration is given to the role that performance-based indicators play in motivating change; the steps needed to develop indicators, including interacting with an industry to secure adequate data for an indicator; and the actual application and use of an indicator when complete. How indicators are employed in the EPA's efforts to encourage industries to voluntarily improve their use of energy is discussed as well. The report describes the data and statistical methods used to construct the EPI for cement manufacturing plants. Individual equations are presented, as are the instructions for using them in an associated Excel spreadsheet.
\end{abstract}

\section{INTRODUCTION}

The ENERGY STAR ${ }^{\circledR}$ program was introduced by the U.S. Environmental Protection Agency (EPA) in 1992 as a voluntary, market-based partnership for reducing air pollution through increased energy efficiency. This government program enables industrial and commercial businesses as well as consumers to make informed decisions that save energy, reduce costs, and protect the environment.

A key step in improving corporate energy efficiency is to institutionalize strategic energy management. The ENERGY STAR guidelines for energy management (EPA 2003), which are 
modeled on the International Organization for Standardization (ISO) quality and environmental standards, identify the components of successful energy management. These include:

- Obtaining the commitment of a senior corporate executive to manage energy across all businesses and facilities operated by the company;

- Appointing a corporate energy director to coordinate and direct the energy program and multidisciplinary energy team;

- Establishing and promoting an energy policy;

- Developing a system for assessing the performance of the energy management efforts, including tracking energy use as well as benchmarking energy in the facilities, operations, and subunits therein;

- Conducting audits to determine areas for improvement;

- $\quad$ Setting goals at the corporate, facility, and subunit levels;

- Establishing an action plan across all operations and facilities, as well as monitoring successful implementation and promoting the value to all employees; and

- Providing rewards for the success of the program.

Of the major steps taken to develop an energy management program, benchmarking energy use (by comparing current energy performance to that of a similar entity) is critical. In manufacturing, benchmarking may take the form of detailed comparisons of specific production lines or pieces of equipment, or it may be performed at a higher organizational level by gauging the performance of a single manufacturing plant with respect to the industry. Regardless of the application, benchmarking enables companies to determine whether better energy performance can be expected. It empowers them to set goals and evaluate their reasonableness.

This report describes the basic concept of benchmarking and the statistical approach employed, more recent experience gained in developing performance-based energy indicators for the cement manufacturing industry, the evolution of the analysis done for this industry, the final results of this analysis, and ongoing efforts by the EPA to improve the energy efficiency of this industry and others. 


\section{BENCHMARKING THE ENERGY EFFICIENCY OF INDUSTRIAL PLANTS}

Among U.S. manufacturers, few industries participate in industrywide plant benchmarking. Some industries support plantwide surveys conducted by a private company, and these industries are provided with benchmarks that address energy use and other operational parameters related to their facilities. Most other industries, however, have not benchmarked energy use across their plants. As a result, some energy managers find it difficult to determine how well their plants might perform. The Portland Cement Association (PCA) does collect data on energy, labor, and production in the cement manufacturing industry and provides member companies with summary statistics on plant energy use (PCA 1997 and various years).

The EPA and Argonne National Laboratory discussed a method for developing benchmarks of energy performance for plant-level energy use within a manufacturing industry. Discussions yielded a plan to use a source of data that would nationally represent manufacturing plants within a particular industry, create a statistical model of energy performance for the industry's plants on the basis of these data and other available sources for the industry, and establish the benchmark on the basis of a comparison of plants implementing best practices, or best-performing plants, to others in the industry. The primary data sources were determined to be the Census of Manufacturing (CM), Annual Survey of Manufactures (ASM), and Manufacturing Energy Consumption Survey (MECS) compiled by the U.S. Bureau of the Census (Census Bureau), supplemented by data provided by trade associations and individual companies on a case-by-case basis.

\subsection{SCOPE OF AN INDICATOR: EXPERIENCE WITH THE CEMENT MANUFACTURING INDUSTRY}

The EPA and Argonne initiated discussions about developing a plant-level benchmark with companies that operate in the cement manufacturing industry, with cooperation from the PCA. Companies with manufacturing plants located in the United States were invited to participate in the discussions.

At the outset, the term "plant benchmark" was discussed. Industry engineers, who routinely develop benchmarks at many levels of plant operation, including the process-unit level, expressed concern that using the word "benchmark" would be confusing and could imply a particular process or tool. For this reason, it was decided that a more descriptive term would be clearer. The term ENERGY STAR plant energy performance indicator (EPI) was adopted.

The EPA and Argonne defined the scope for the EPI. It is a plant-level, not a processspecific, indicator, and it relates plant inputs (in terms of all types of energy use) to plant outputs (as expressed in a unit of production). The EPA relied on a Lawrence Berkeley National Laboratory (LBNL) study of the cement manufacturing industry (Worrell and Galitsky 2004) to define the energy focus of the model. The LBNL report provides a summary of the primary operations within cement plants: kiln feed preparation, clinker production (pyro-processing), and finish grinding. However, even though most cement manufacturing plants are located near a 
long-term source of raw materials that is typically owned and operated by the same company, mining and quarrying were not included in the scope of the EPI.

The model was designed to account for major, measurable impacts that affect a plant's energy use. The starting point for EPI development was Census Bureau data for industrial plants. For the cement industry, these data included information on energy use, labor hours, and the quantities of major products produced at a plant. The total capacities and number of kilns in plants were included to account for the fixed and variable components of plant operation.

\subsection{DATA SOURCES}

This analysis uses confidential plant-level data from two sources: the Longitudinal Research Database (LRD), which is maintained by the Census Bureau's Center for Economic Studies (CES), and the PCA. The LRD includes nonpublic, plant-level data that are the basis of government-published statistics on manufacturing. The CES constructed a panel of plant-level data from the ASM and CM. The LRD covers economic activity (e.g., labor, energy, plant and equipment, costs of materials, and total shipment value of output) for a sample of plants during the survey years, and it provides complete coverage during the years of the economic census.

Under Title 13 of the U.S. Code, these data are confidential. However, CES allows academic and government researchers with special sworn status to access these confidential micro data under its research associate program. The confidentiality restrictions prevent the disclosure of any information that would allow for the identification of a specific plant's or firm's activities. Aggregate figures or statistical coefficients that do not reveal the identity of individual establishments or firms can be released publicly. The use of plant-level data rather than aggregate data significantly enhances the value of the information that can be obtained about economic performance, particularly when the issue of energy efficiency is being examined.

The energy, labor, and production data were taken from the CM for 1997 for North American Industry Classification System (NAICS) code 32731 - cement manufacturing. Because the product mix was expected to have an impact on energy use, Census Bureau data on product mix for different types of cement — including ASTM (American Society for Testing and Materials) type 1, 2, 3, 4, and 5 cements, masonry, and other cement - were used. Production data were given in terms of physical quantities (short tons) for various types of cement shipped. Labor data were given in terms of production worker hours, adjusted for the cost of salaried and contract employment. The result is an estimate of total hours worked at the plant by all types of personnel. For each plant in the CM, the data on the cost of fuels were merged with the data on energy prices and energy mix by fuel type from the 1998 MECS. An average price of energy was constructed from the MECS data. This price was applied to the cost of fuels reported in the CM, after adjusting for inflation. Data on electricity are directly reported in the CM in kilowatt-hours. To calculate total primary energy, this electricity was converted to Btu by applying a conversion factor of 10,236 Btu per $1 \mathrm{kWh}$, or, alternately, 1 Btu of electric power (site) = 3 Btu of electric power (primary). This was added to the estimates of fuel use in Btu. Data on kiln capacities and numbers of kilns were taken from PCA summaries (PCA 1997 and various years). The PCA 
surveys its membership, which constituted $90-95 \%$ of total U.S. capacity during the 1990s. The response rate of its members to its surveys is $90-100 \%$.

This linking of data means that finish grinding plants and companies that were not members of the PCA were excluded from the analysis. However, given the wide coverage of the PCA surveys, it is not expected that these exclusions would introduce any significant bias to the estimates. In addition, finish grinding plants are relatively few in number and are much less energy intensive than their integrated counterparts. In a latter stage of the analysis, confidential data from the PCA's Labor and Energy Survey were provided to Argonne under a cooperative nondisclosure agreement. This information was the source of data for waste-derived forms of energy (e.g., tires and other solid wastes that could be burned in a kiln for energy).

\subsubsection{PCA Energy Data}

Cement kilns can burn a variety of wastes, such as old tires and municipal solid waste, as a source of fuel. During the early stages of this analysis, there was concern that the energy data derived from the CM and MECS might underreport these unconventional waste-derived fuels. The PCA also conducts a survey of energy use. Since the PCA is likely to be more familiar with the unusual fuel use patterns in cement plants than the Census Bureau is, we arranged to compare the PCA and MECS data. Under a nondisclosure agreement with the PCA, plant-level data for energy use were provided to Argonne and matched to Census Bureau plant-level data. To assess the correspondence of the PCA and MECS data, we computed a correlation coefficient and produced kernel density plots of the ratio of the PCA-reported fuel use to the MECS-reported fuel use. Table 1 gives the correlation coefficients between the PCA and MECS plant-level data for energy use. The concern about waste fuels was confirmed, but the reliability of the MECS data for conventional fuels (particularly electricity, coal, and natural gas) was also confirmed. The correlation for waste fuels was very low, as was the correlation for fuels other than electricity, coal, and gas. These fuels are predominantly fuel oils and liquefied petroleum gas (LPG), which are used to only a small degree.

TABLE 1 Correlation Coefficient between PCA and MECS Plant-Level Energy Data

\begin{tabular}{clc}
\hline $\begin{array}{c}\text { Part of } \\
\text { Figure } 1\end{array}$ & \multicolumn{1}{c}{ Energy Source } & $\begin{array}{c}\text { Correlation } \\
\text { Coefficient }\end{array}$ \\
\hline A & Total waste fuels & \\
B & Total fuel & 0.32 \\
C & Total fuel without waste fuels & 0.39 \\
D & Other nonwaste fuels (excludes electricity, coal, and natural gas waste) & 0.94 \\
E & Electricity & 0.81 \\
F & Natural gas & 0.99 \\
G & Coal & 0.99 \\
\hline
\end{tabular}




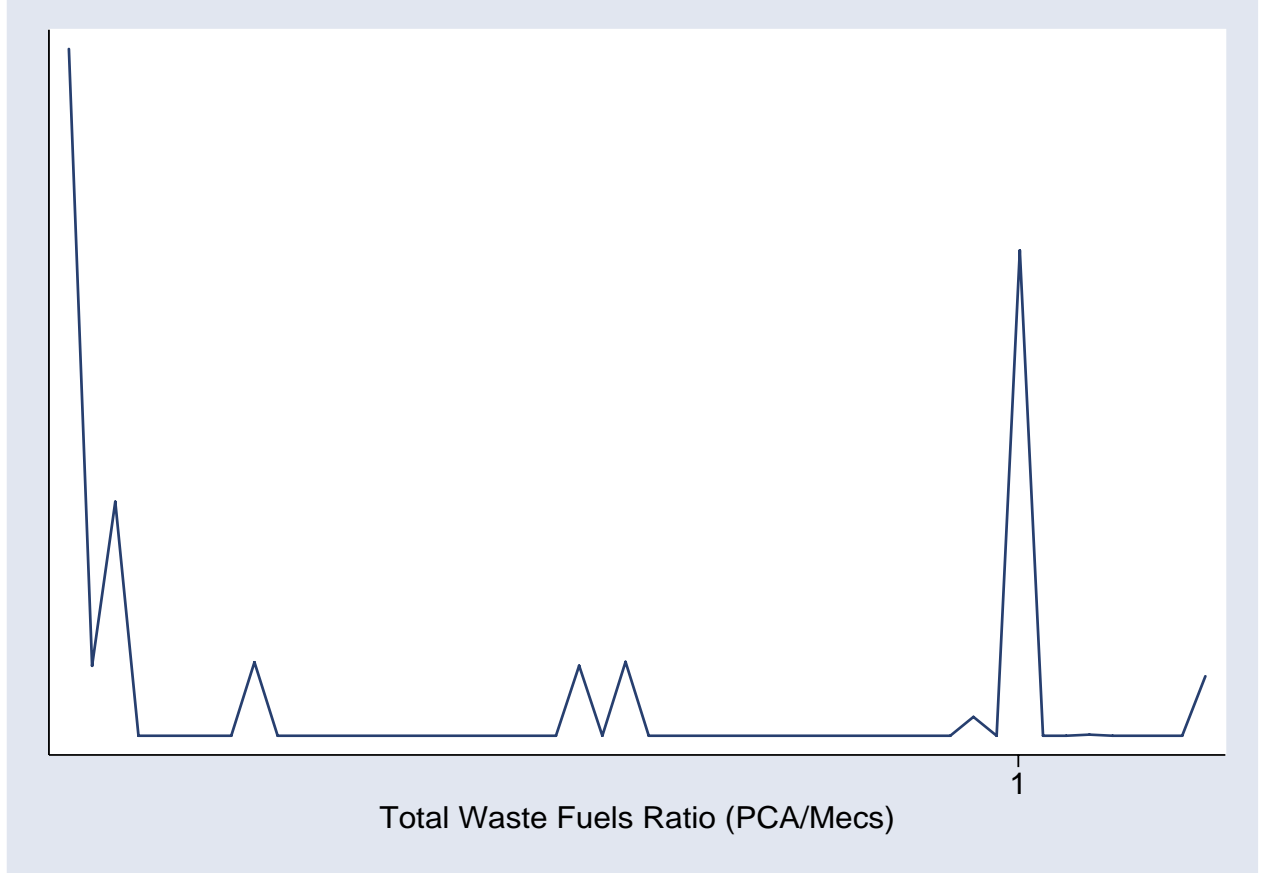

A

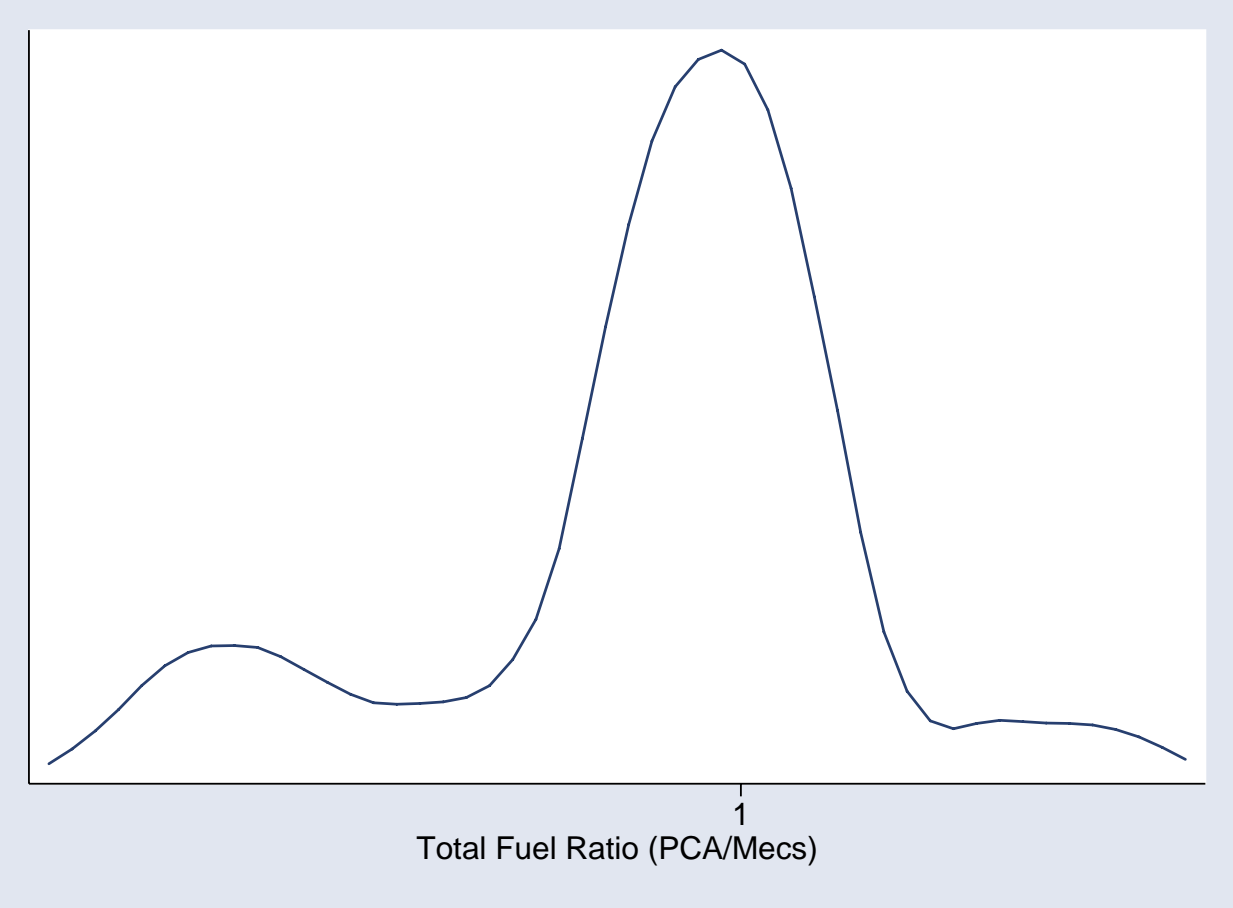

B

FIGURE 1 Kernel Density Plot of the Ratio of PCA to MECS Data for the Energy Sources 


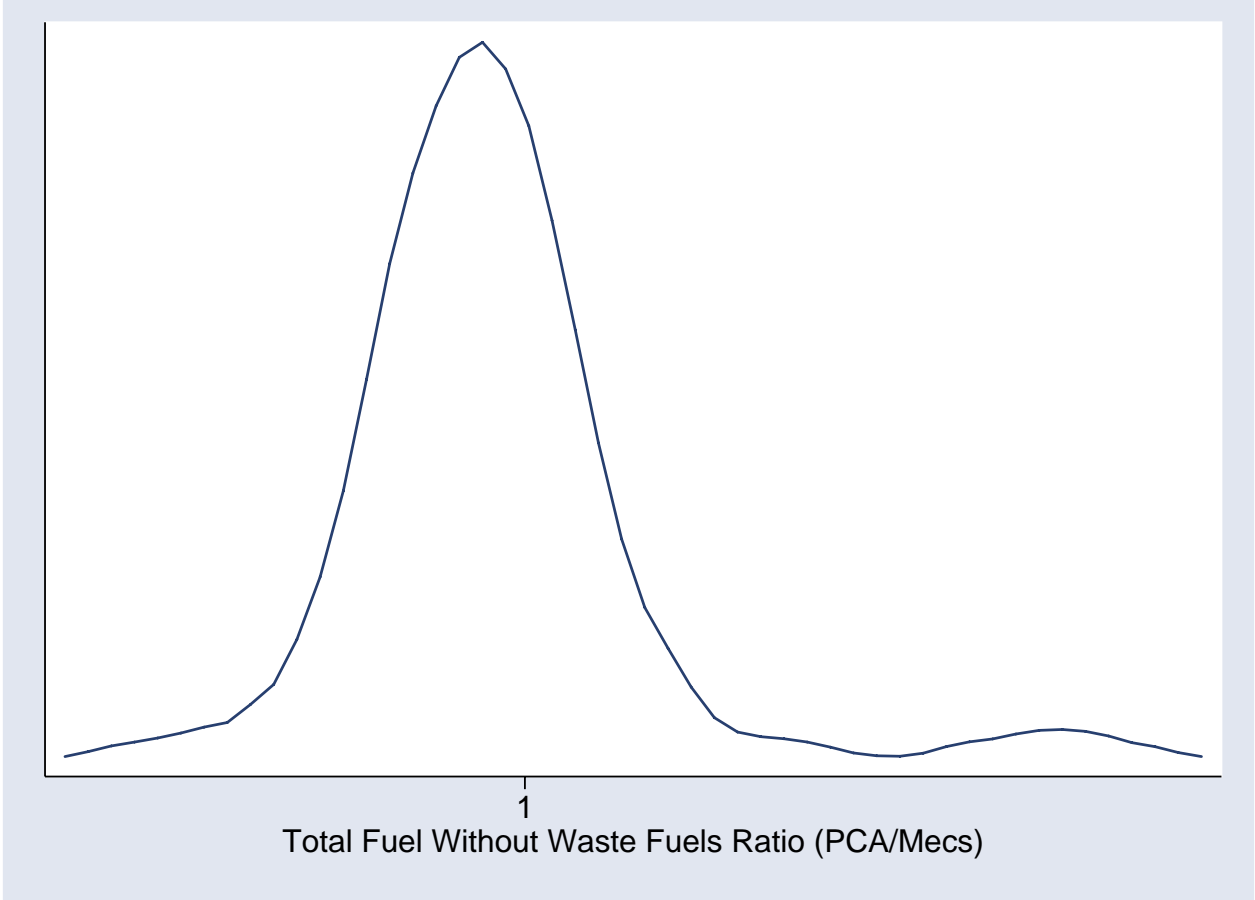

C

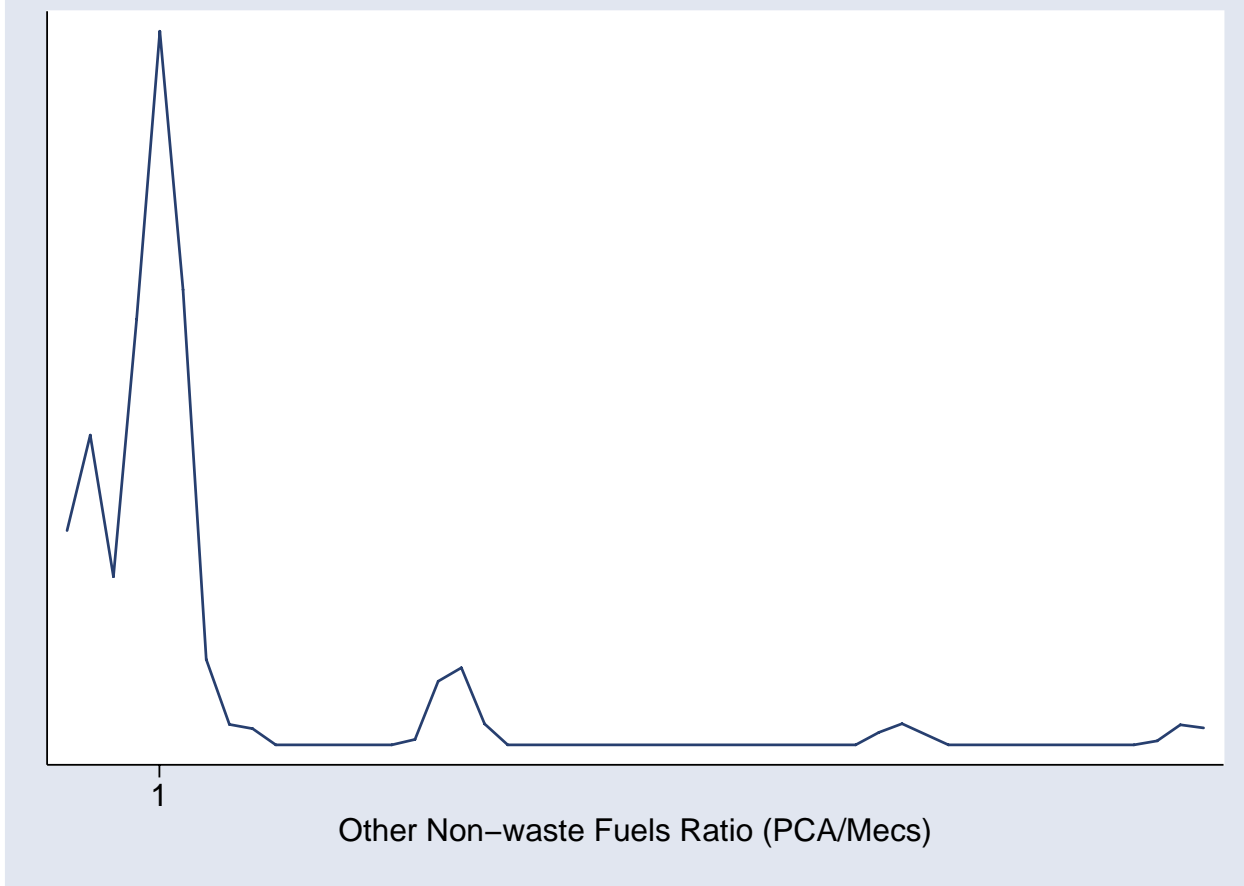

D

FIGURE 1 (Cont.) 


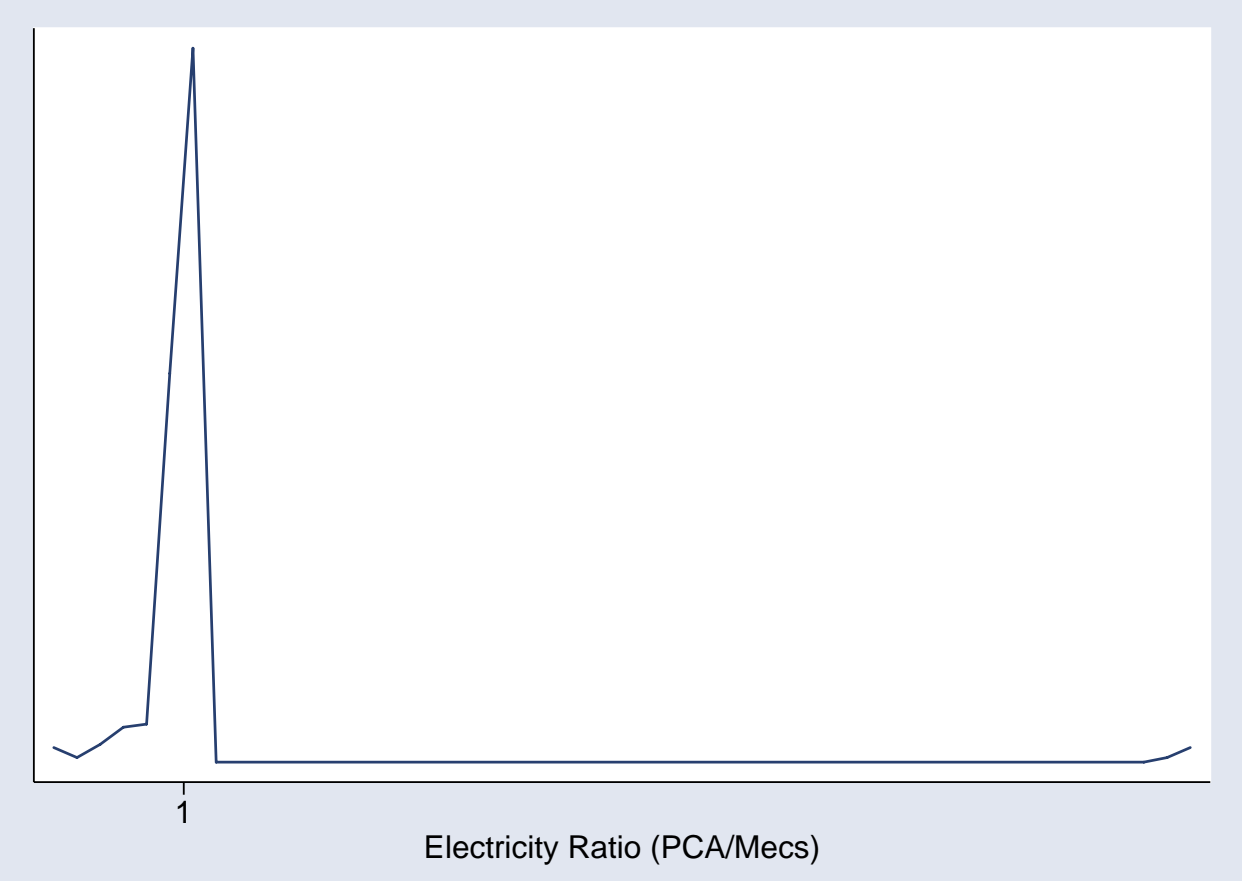

$\mathbf{E}$

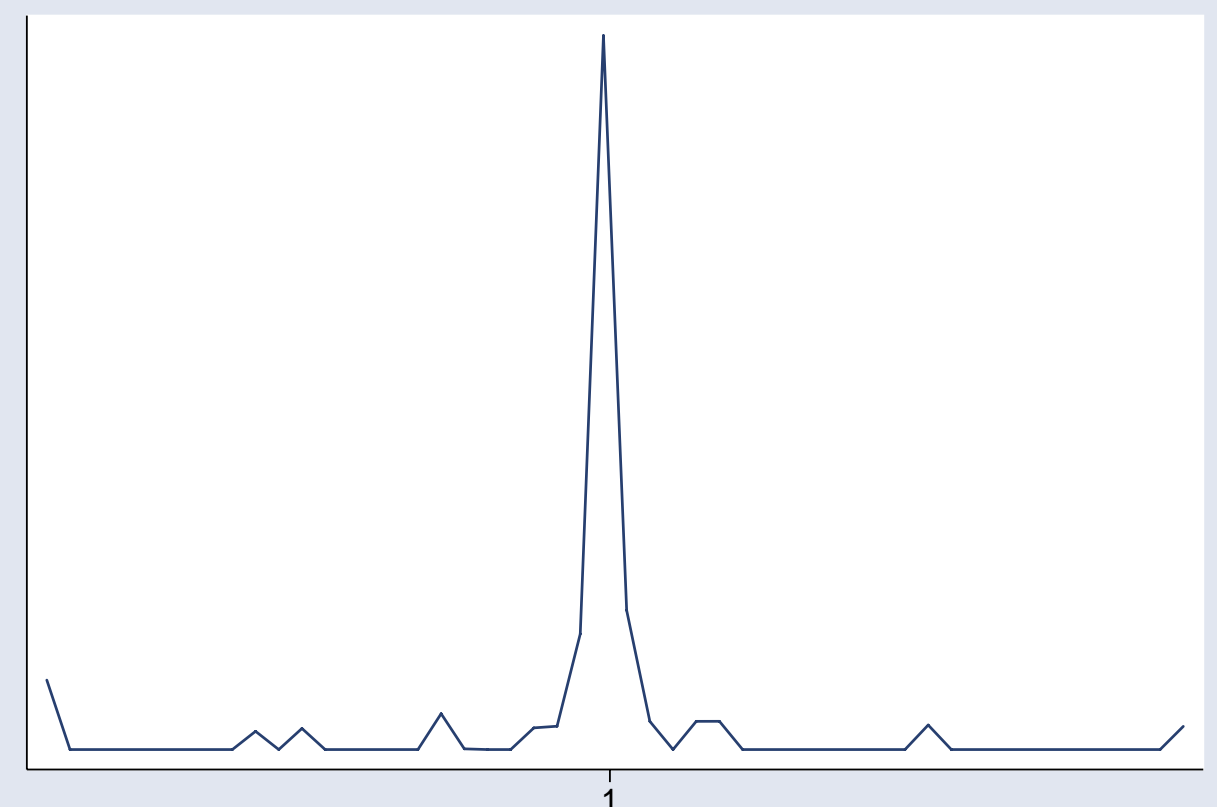

Natural Gas Ratio (PCA/Mecs)

F

FIGURE 1 (Cont.) 


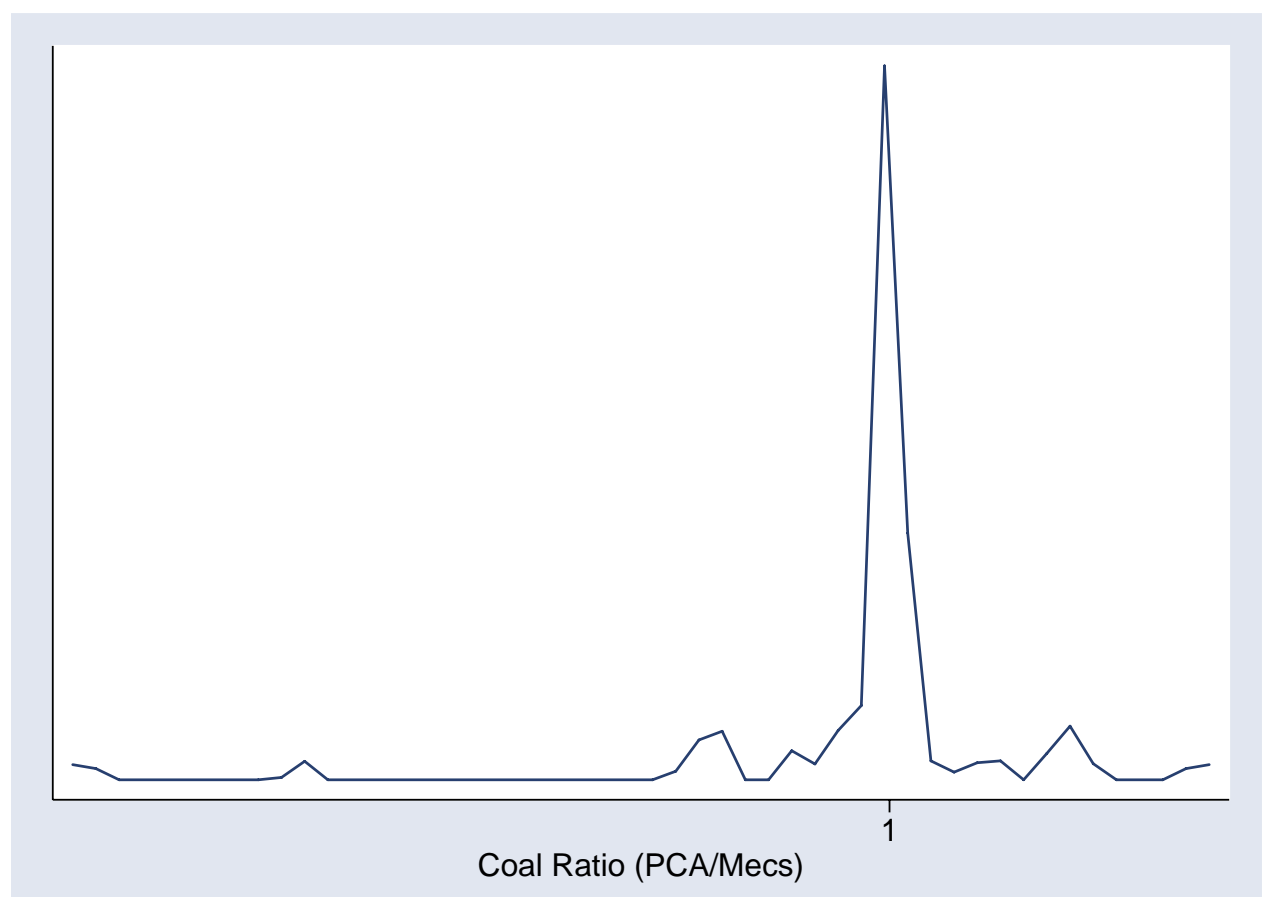

G

FIGURE 1 (Cont.)

To aid in further understanding the distribution of reported MECS and PCA data, we constructed kernel density plots of the ratio of PCA data to MECS data. ${ }^{1}$ These plots are shown in Figure 1 for each fuel type. Total waste fuels show a marked pattern of underreporting. In particular, when MECS data were zero, the ratio could not be computed, so, for the purpose of plotting, the ratio was set to zero. On the basis of this analysis, we determined to use the PCA estimates instead of the MECS data for waste-derived fuels. For all other types of energy, however, we used the MECS data.

Matching the MECS data to the PCA data reduced the number of observations used for the analysis. Other plants were dropped from the analysis because of irreconcilable discrepancies in the data, like missing values for key inputs for labor or production. The result is that 46 observations were included in the analysis. Since the PCA identified 105 plants in operation in 1997, we can conclude that our matching process was able to link about half of those 105 plants (i.e., 46 plants). While we would have liked to match a higher percentage, we also have no reason to expect that the missing observations are systematically related to the energy issues we are analyzing statistically. In other words, we do not believe either that the excluded plants would have higher (or lower) energy efficiencies or that the results would be biased by their exclusion. Sample statistics for the final data set used in this analysis are shown in Table 2.

1 Disclosure requirements prevent us from giving the scale of the kernel density plots. Nevertheless, the plots still illustrate the nature of the distributions. 
TABLE 2 Sample Means for Selected Variables

\begin{tabular}{lc}
\hline \multicolumn{1}{c}{ Variable } & Sample Mean \\
\hline & \\
Total primary energy $\left(10^{6} \mathrm{Btu}\right)$ & $4,737,263$ \\
Capacity (short tons) & 881,385 \\
Number of kilns & 1.47 \\
Worker hours $\left(10^{3}\right)$ & 346 \\
Cement production (short tons) & 846,098 \\
\hline
\end{tabular}




\section{STATISTICAL APPROACH}

The goal of this study was to develop an estimate of the distribution of energy efficiency across the industry. Efficiency is the difference between actual energy use and "best practice" energy use (i.e., the lowest energy use achievable). The efficiency that is achievable is influenced by operating conditions, which vary among plants, so the measure of best practice must take these conditions into account. Statistical models are well-suited for accounting for these types of observable conditions but typically focus on average practice, not best practice. However, stochastic frontier regression analysis is a tool that can be used to identify best practice. This section provides the background on the stochastic frontier, a discussion on the review process and evolution of the model's equations, and the final model estimates.

\subsection{STOCHASTIC FRONTIER}

The concept of the stochastic frontier analysis that supports the EPI can be easily described in terms of the standard linear regression model, which is reviewed in this section. A more detailed discussion on the evolution of the statistical approaches for estimating efficiency can be found in Greene (1993). Consider at first the simple example of a production process that has a fixed energy component and a variable energy component. A simple linear equation for this can be written as

$$
E_{i}=\alpha+\beta y_{i}
$$

where

$$
\begin{aligned}
& E=\text { energy use of plant } i \text { and } \\
& y=\text { production of plant } i .
\end{aligned}
$$

Given data on energy use and production, the parameters $\alpha$ and $\beta$ can be fit via a linear regression model. Since the actual data may not be perfectly measured, and since this simple relationship between energy and production may be only an approximation of the "true" relationship, linear regression estimates of the parameters rely on the proposition that any departures in the plant data from Equation 1 are normally distributed. This implies that the actual relationship, represented by Equation 2, includes an error term $\varepsilon$ that follows a normal (bellshaped) distribution with a mean of 0 and variance of $\sigma^{2}$. In other words, about half of the actual values of energy use are less than what Equation 1 would predict, and half are greater.

$$
\begin{gathered}
E_{i}=\alpha+\beta y_{i}+\varepsilon_{i} \\
\varepsilon \sim N\left(0, \sigma^{2}\right)
\end{gathered}
$$

The linear regression gives the average relationship between production and energy use. If the departures from the average, particularly those that are above the average, are due to 
energy inefficiency, we would be interested in a version of Equation 1 that gives the "best" (lowest) observed energy use. A regression model can find the line that best explains the average response of energy use per unit of production. The relationship between the lowest energy use per unit of production and changes in utilization can be obtained by shifting the line downward so that all the actual data points are on or above the line. This "corrected" ordinary least squares (COLS) regression is one way to represent the frontier.

While the COLS method is appealing in terms of its simplicity, a more realistic view is that not all the differences between the actual data and the frontier are due to efficiency. Since we recognize that there may still be unobservable errors in data collection and/or reporting, that there may be effects that are unaccounted for in the analysis, and that a linear equation is an approximation of the complex factors that determine manufacturing energy use, we still wish to include the statistical noise (i.e., "random error") term $v_{i}$ in the analysis, but we also want to add a second random component $u_{i}$ to reflect energy inefficiency. ${ }^{2}$ Unlike the statistical noise term, which may be positive or negative, this second error term will follow a one-sided distribution. If we expand the simple example of energy use and production to include a range of potential effects, we can write a version of the stochastic frontier model as energy use per unit of production as a general function of systematic economic decision variables and external factors:

$$
\begin{gathered}
E_{i}=h\left(X_{i}, Y_{i}, Z_{i} ; \beta\right)+\varepsilon_{i} \\
\varepsilon_{i}=u_{i}-v_{i} \\
v \sim N\left[0, \sigma_{v}^{2}\right],
\end{gathered}
$$

where

$$
\begin{aligned}
E= & \text { energy use, either electricity, nonelectric energy, or total site energy (TSE, } \\
& \text { the total measure of fuel and electricity); } \\
Y= & \text { production, measured by physical production; } \\
X= & \text { systematic economic decision variables (i.e., labor hours worked, materials } \\
& \text { processed, plant capacity, or utilization rates); } \\
Z= & \text { systematic external factors (i.e., heating and cooling loads); and } \\
\beta= & \text { all the parameters to be estimated. }
\end{aligned}
$$

We assume that energy (in)efficiency $u$ is distributed according to one of several possible onesided statistical distributions $^{3}$ (e.g., gamma, exponential, truncated normal). It is then possible to

2 "Random" means that this effect is not directly measurable by the analyst but can be represented by a probability distribution.

3 We also assume that the two types of errors are uncorrelated: $\sigma_{u, v}=0$. 
estimate the parameters of Equation 3, along with the distribution parameters of $u$, as well as to test for the differences in a model based on this more complex pair of distributions versus the simpler view presented in Equation 3.

One advantage of the approach is that the parameters used to normalize for systematic effects and describe the distribution of efficiency are jointly estimated. The standard regression model captures the behavior of the average, but the frontier regression captures the behavior of the best performers. For example, if the best performing plants were less sensitive to capacity utilization because they used better shutdown procedures, then the estimated slope of the frontier capacity utilization curve would not be as steep as the slope for the average plants.

Given data for any plant, we can use Equation 3 to compute the difference between the actual energy use and the predicted frontier energy use:

$$
E_{i}-h\left(X_{i}, Y_{i}, Z_{i} ; \beta\right)+v_{i}=u_{i} .
$$

Since we have estimated the probability distribution of $u$, Equation 5 represents the probability that the plant inefficiency is greater than this computed difference:

$$
\begin{gathered}
\text { Probability [energy inefficiency } \left.\geq E_{i}-h\left(X_{i}, Y_{i}, Z_{i} ; \beta\right)+v_{i}\right]= \\
1-F\left[E_{i}-h\left(X_{i}, Y_{i}, Z_{i} ; \beta\right)+v_{i}\right] .
\end{gathered}
$$

$F()$ is the cumulative probability density function of the appropriate one-sided density function (e.g., gamma, exponential, truncated normal). The value $1-F()$ in Equation 5 defines the EPI score and may be interpreted as a percentile ranking of the energy efficiency of the plant. In practice, we can measure only $E_{i}-h\left(X_{i}, Y_{i}, Z_{i} ; \beta\right)=u_{i}-v_{i}$, so this implies that the EPI score $1-F\left[E_{i}-h\left(X_{i}, Y_{i}, Z_{i} ; \beta\right)\right]=1-F\left(u_{i}-v_{i}\right)$ is affected by the normally distributed component of $v_{i}$; that is, the score will reflect other influences that are not accounted for by the function $h(*)$. Since this ranking is based on the distribution of inefficiency for the entire industry but normalized to the specific systematic factors of the given plant, this statistical model allows the user to answer the hypothetical but very practical question, "How does my plant compare to everyone else's in my industry, if all other plants were similar to mine?"

\subsection{EVOLUTION OF THE MODEL}

The model evolved over a period of time on the basis of comments from industry reviewers and subsequent analyses. Industry participants tested each version of the model. Companies were asked to input actual data on all of their plants and to then determine whether the results were consistent with any energy efficiency assessments that might have been made for these plants. The resulting comments were considered in order to improve the EPI.

A variety of specifications, including various aggregations and disaggregations of the product categories, were tried. The preferred model was cleared by the Census Bureau for release 
to the public. During the industry testing and evaluation process, a number of issues were raised with regard to feedstock quality, the use of kiln by-pass to produce low-alkali cement, and altitude effects. From those who participated in the conference calls, a working group from the industry was established to address questions raised about by-pass and other issues.

One proposal was that the EPI should give an "energy credit" to plants that have to use kiln by-pass, since by-pass is sometimes required to produce low-alkali cement or for other environmental controls. However, it was determined that since other methods are available to achieve these production goals, giving an energy credit for by-pass would not produce the kind of "level comparison" that is needed.

Other issues related to differences in feedstocks were raised. Specifically addressed was the hardness of the limestone feed to the kiln. Although industry participants felt that hardness affects the process energy requirements, hardness is not routinely measured, nor is there any common industry standard for it. The degree of hardness can also vary within or among the strata of rock in a given quarry; thus, it may change frequently within a year, which is the time span of the analysis. Similar issues were raised regarding moisture content. Moisture also affects process energy requirements, but no routinely collected data on this dimension of feedstock quality were available across the industry. The PCA is considering whether to collect data on hardness and moisture. Until such an industrywide data source exists, it is not feasible to include these feedstock dimensions in the EPI. Because of the lack of consistent data on both of these variables, it was not possible to consider them in the final model. To the extent that these variables are distributed randomly and are not correlated with other effects included in the model, they will be part of estimated variance in the error term.

It is also possible that altitude, and its associated impact on the amount of oxygen available for combustion, might have an impact on process energy requirements. A set of data on altitude, based on plant location, was compiled and included in the analysis. This variable was found to not be statistically significant and was not included in the final version.

\subsection{MODEL ESTIMATES}

For simplicity, we assume that the function $h()$ is log-linear in the parameters and allows for linear terms for the product mix. Several alternatives for the distribution of the inefficiency term $u$ were tried. In the final version of the EPI, the more complex approach based on Equation 3 was not found to be statistically superior to the simpler approach based on Equation 2, so the COLS estimates based on Equation 2 were used.

$$
\begin{aligned}
E_{i}= & \beta_{0}+\beta_{1} \ln (\text { capacity })+\beta_{2} \ln (\text { labor hours })+\beta_{3} \ln (\text { total cement production }) \\
& +\beta_{4} \ln (\text { number of kilns })+\beta_{5}(\% \text { masonry })+\beta_{6}(\% 4 \text { or other }) \\
& +\beta_{7}(\% \text { wet })+\varepsilon_{i},
\end{aligned}
$$


where

$$
\begin{aligned}
& E \quad=\text { total primary energy use }\left(10^{6} \mathrm{Btu}\right) ; \\
& \text { capacity }=\text { kiln capacity (short tons per year); } \\
& \text { labor hours }=\text { total hours, including production, } \text { contract and salaried; } \\
& \text { total cement } \\
& \text { production }=\text { cement production (short tons); } \\
& \text { number of } \\
& \text { kilns } \quad=\text { total number of operating kilns at the plant; } \\
& \% \text { masonry = ratio of masonry cement to total production; } \\
& \% 4 \text { or other }=\text { ratio of ASTM } 4 \text { or other cement to total production; } \\
& \% \text { wet } \quad=\text { ratio of wet kiln capacity to total capacity; and } \\
& \beta \quad=\text { vector of parameters to be estimated. }
\end{aligned}
$$

The variable $\varepsilon$ is distributed as $N\left(0, \sigma_{\varepsilon}^{2}\right)$.

Since the frontier approach was not found to be superior to COLS, we can use Equation 3 to compute the difference between the actual energy use and the predicted frontier energy use, and we can use the estimated normal probability distribution of $\varepsilon$ to represent the probability that the plant inefficiency is greater than this computed difference:

$$
\begin{gathered}
\text { Probability [ energy inefficiency } \left.\geq E_{i}-h\left(X_{i}, Y_{i}, Z_{i} ; \beta\right)\right] \\
=1-F\left[E_{i}-h\left(X_{i}, Y_{i}, Z_{i} ; \beta\right)\right] .
\end{gathered}
$$

$F()$ is then the cumulative probability density function of the estimated normal distribution. The value $1-F($ ) in Equation 7 defines the EPI score and may be interpreted as a percentile ranking of the energy efficiency of the plant. Parameter estimates made by using COLS are given in Table 3. 
TABLE 3 Total Primary Energy Model Estimatesa

\begin{tabular}{lccc}
\hline \multicolumn{1}{c}{ Variable Name } & Coefficient & Standard \\
Error & $\mathrm{t}$ \\
\hline \% ASTM 4 or other & 0.726358 & 0.546131 & 1.33 \\
\% masonry & 0.639876 & 0.381003 & 1.68 \\
Capacity & 0.435109 & 0.106956 & 4.07 \\
Number of kilns & 0.104809 & 0.063681 & 1.65 \\
Labor hours & 0.139776 & 0.104207 & 1.34 \\
Total cement production & 0.334777 & 0.103442 & 3.24 \\
\% wet & 0.154948 & 0.068257 & 2.27 \\
Constant & 3.607467 & 0.893352 & 4.33 \\
\hline
\end{tabular}

a Number of observations $=46$, and R-squared $=0.82$. 


\section{JUDGING THE ENERGY EFFICIENCY OF CEMENT MANUFACTURING PLANTS}

\subsection{HOW THE EPI WORKS}

The cement manufacturing EPI scores the energy efficiency of a cement manufacturing plant based in the United States. To use the tool, the following information must be available for a cement plant:

1. Energy purchases

Data are needed by type of energy (e.g., electricity or fuel) for the current year and a baseline year as defined by the user.

- Electricity: Data for electricity should include only total electricity purchased or transferred into the plant from another facility. Units should be supplied in terms of site energy (in kilowatt-hours or million Btu on the basis of 3,412 Btu per $1 \mathrm{kWh}$ ). When total primary energy is calculated, electricity is converted on the basis of 10,236 Btu per $1 \mathrm{kWh}$, or, alternately, 1 Btu of electric energy (site) = 3 Btu of electric energy (primary). Note: If compressed air is transferred in from another facility or central utility in the plant, then that consumption should be converted back to kilowatt-hours by using plant average conversion efficiencies.

- Nonelectric energy use: All other forms of energy should be included. When total primary energy is calculated, 1 Btu of nonelectric energy (site) $=1 \mathrm{Btu}$ of nonelectric energy (primary). Note: If steam is transferred in from another facility or central utility in the plant, then the consumption should be converted back to Btu by using plant average boiler conversion efficiencies.

- Energy costs: The information on energy costs can be input by the user. These costs do not affect the EPI score for a plant but are included to enable the costs of energy to be estimated at various potential levels of energy efficiency. They are included in the spreadsheet when the EPI is used as a management tool.

2. Plant location zip code

Zip codes are used to determine default values for state-level average energy prices.

3. Total amount of clinker produced during the year

4. Maximum amount of clinker that can be produced per day

This amount represents what the plant is capable of processing. The annual capacity is defined on the basis of the assumption that there are 38.7 days of downtime. 
5. Sum of the amounts of ASTM 1,2,3, and 5 cements produced during the year

6. Total amount of ASTM 4 cement produced during the year

7. Total amount of masonry cement produced during the year

8. Total amount of all other types of cement produced during the year

9. Total amount of production worker and contract worker hours during the year This is the number of production and contract employees multiplied by the average number of hours worked during the year. The industry average of 0.24 hour per ton of cement can be used as a default value when plant-specific labor data are not readily available. This information provides another measure of plant utilization.

On the basis of these data inputs, the EPI will report a score for the plant in the current and baseline years that reflects the relative energy efficiency of the plant compared to that of the industry. It is a percentile score on a scale of 0 to 100. Plants that score 75 or better are classified as efficient. (ENERGY STAR defines the 75th percentile as efficient.) A score of 75 means a particular plant is performing better than $75 \%$ of the plants in the industry.

The model also reports on the average plant in the industry (defined as the 50th percentile). Aside from scoring, an industrial user can determine the energy output ratio (million Btu per ton of clinker) and an annual energy cost (dollars per year) for a plant, calculated from national cost figures for the current and baseline years and for average and efficient plants. Although the underlying model was developed from data for U.S.-based plants, the tool does not contain or reveal any confidential information.

\subsection{SPREADSHEET TOOL}

To facilitate the review and use of data by industry energy managers, a spreadsheet was constructed to display the results of the EPI for an arbitrary 4 set of plant-level inputs. The spreadsheet accepts the raw plant-level inputs described above, computes the values for $h($ ) given in Equation 6, and then displays the results from the distribution functions for the total primary energy model presented in Equation 7. The results are based on user-input values for the basic model input described above. By graphically displaying the results, the spreadsheet helps energy managers compare the magnitude of the systematic effects attributable to changes in those inputs on the estimated industry distribution. The energy managers were encouraged to input data for their own plants and then provide comments. A version of this spreadsheet, dated June 1, 2006, which corresponds to the results described in this report, is available from the EPA ENERGY STAR Web site at http://www.energystar.gov/industry. An example of the input

4 In other words, for plant data that may not have originally been in the data set used to estimate the model equations. 
section of the spreadsheet is shown in Figure 2. The results section for total primary energy use is shown in Figure 3.

The EPI score for cement plants uses both production volume and capacity to set the benchmark. Capacity can be difficult to define precisely. However, if the model is sensitive to the value for capacity that has been input, users should be given as much guidance as possible on how to estimate annual capacity. The primary issue is to determine how sensitive the model is to capacity measures. The secondary issue is to determine what approach would be appropriate for estimating what the annual capacity would be.

From a statistical perspective, the EPI score is sensitive to capacity. There is a statistically significant relationship between plant size and energy use. However, the more important question is, "How large is the effect?" There is no single answer to this question, because the model is not linear. The effect varies depending on the level of the EPI score. Figure 4 illustrates this effect. It shows how the EPI score changes if capacity is varied by $1 \%$ (while energy and production levels are held fixed). We see that for a substantial middle range of the model output, the effect is nearly one to one. Another way to look at this result is shown by a simple comparative exercise. If a plant was operating at the 50th percentile, but alternative methods of measuring capacity resulted in a $\pm 10 \%$ difference, the EPI score would vary between the 39th and 61st percentiles. The need to provide guidance to the users of the EPI on measuring capacity is clear.

The EPI analysis used data reported to the PCA to measure capacity. Annual capacity, as collected by the PCA, is defined as the total daily capacity of all kilns multiplied by 365 days minus the annual amount of normal downtime due to maintenance, repair, and cleanup. This approach requires estimates of daily capacity and normal downtime. Solid empirical information based on actual industry data is needed to support this definition and guide EPI users.

The first item, daily capacity, may require some judgment, since the nameplate (design) capacity of a kiln may be modified by subsequent retrofits. However, operating experience probably provides a good basis for estimating capacity from average daily throughput over the year. On a kiln-specific basis, there should not be large variations in daily throughput; therefore, the average over the year should be a reasonable measure of capacity. The maximum daily throughput may be an even better measure of daily capacity. There is likely to be more variance in what is considered "normal" downtime for kilns in different plants across the industry. There is evidence of downtime ranging from 69 to 17 days on the basis of the daily and annual capacity estimates reported to the PCA (2001 data). An analysis of 10 years of data provided by the PCA Economic Analysis Department shows that the mean downtime is 38.7 days. There is no evidence that this amount differs statistically between wet and dry kiln plants. The 38.7-day average is used in the final EPI.

A user-provided estimate of the daily capacity of all kilns, multiplied by 365 days minus the average downtime across all plants in the PCA database, is used for measuring capacity in the cement manufacturing industry EPI. The users input the total daily capacity for all kilns, and the model internally computes the annual capacity by multiplying by 365 days minus the average downtime across all facilities. 


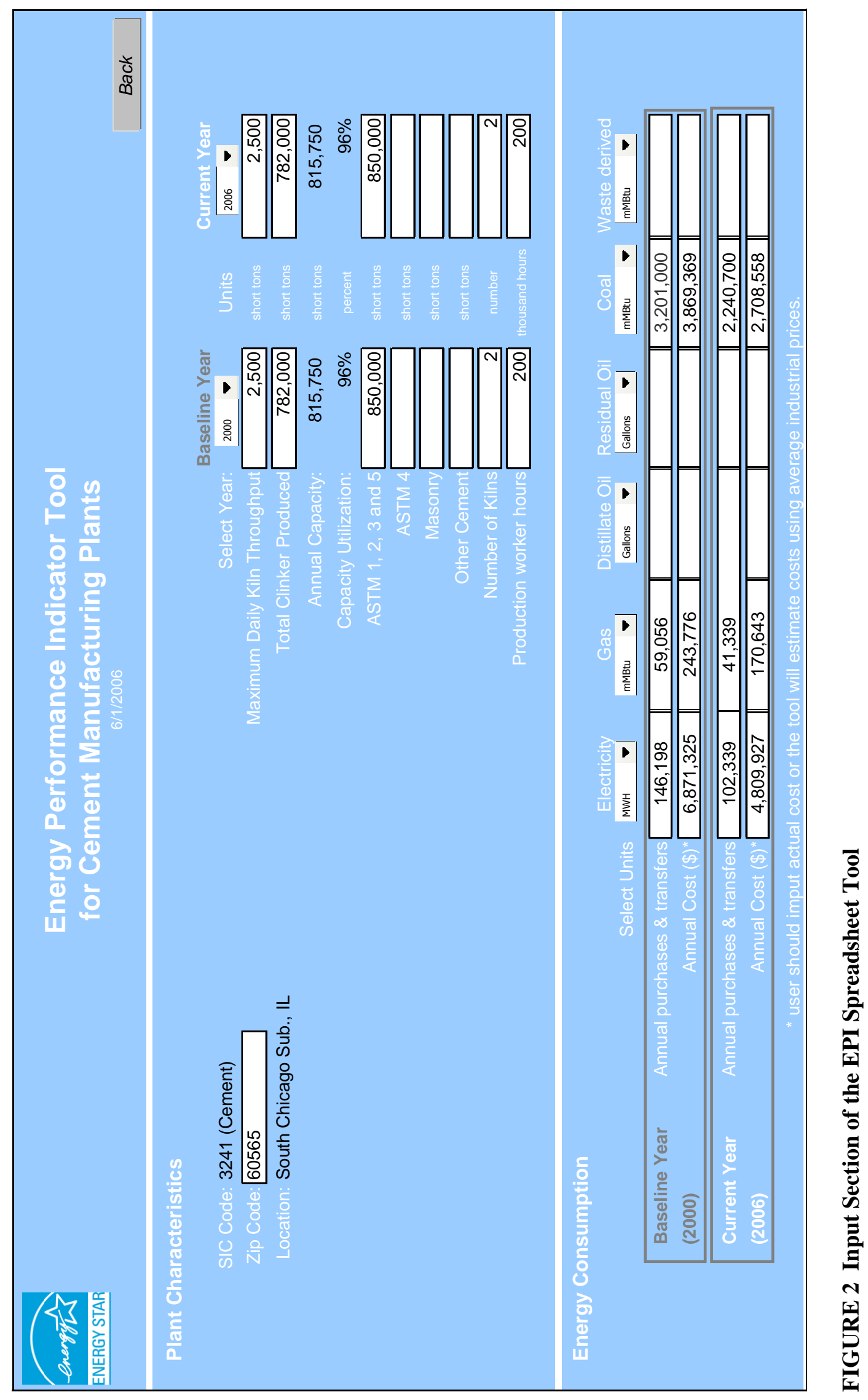




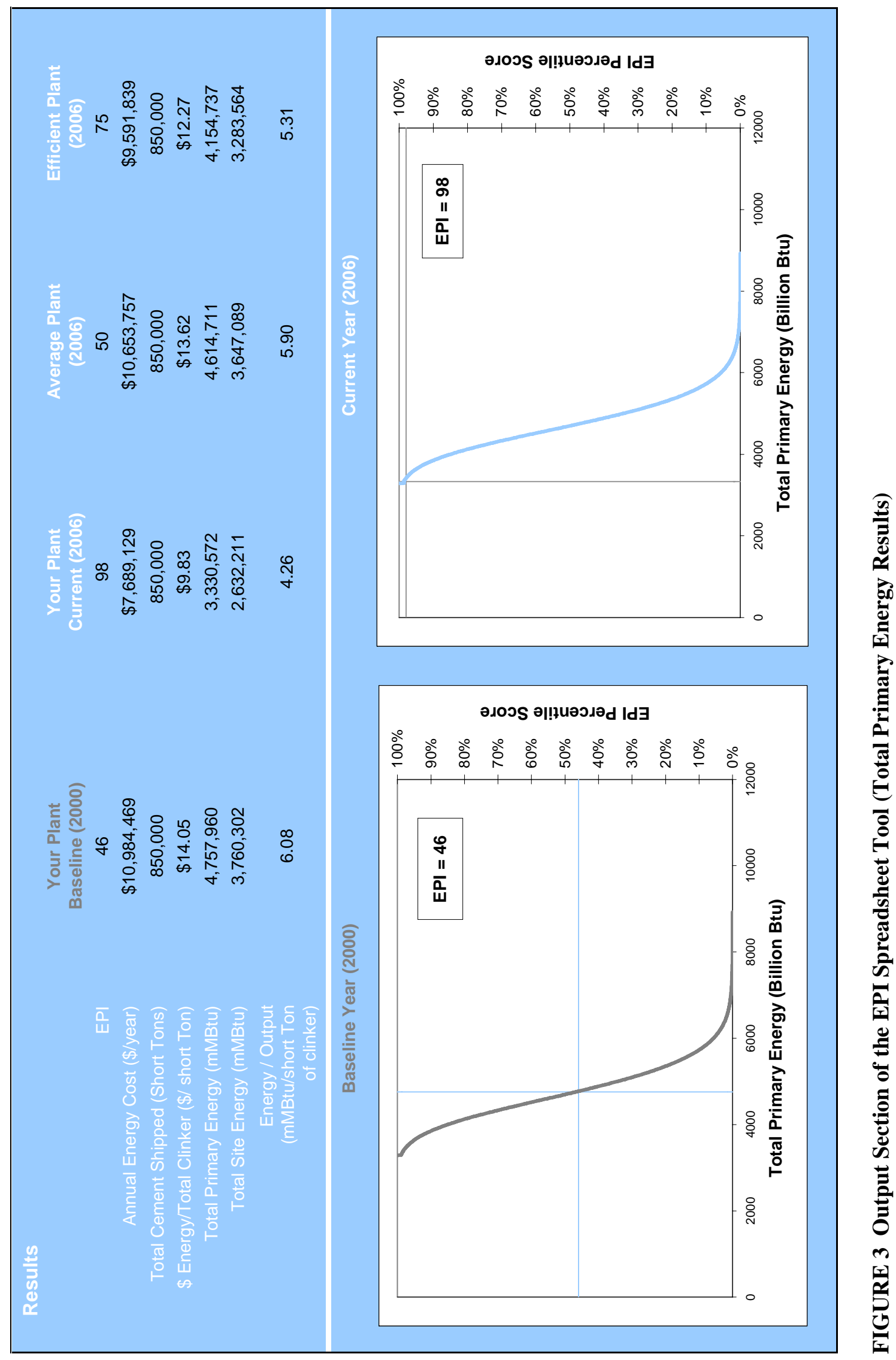




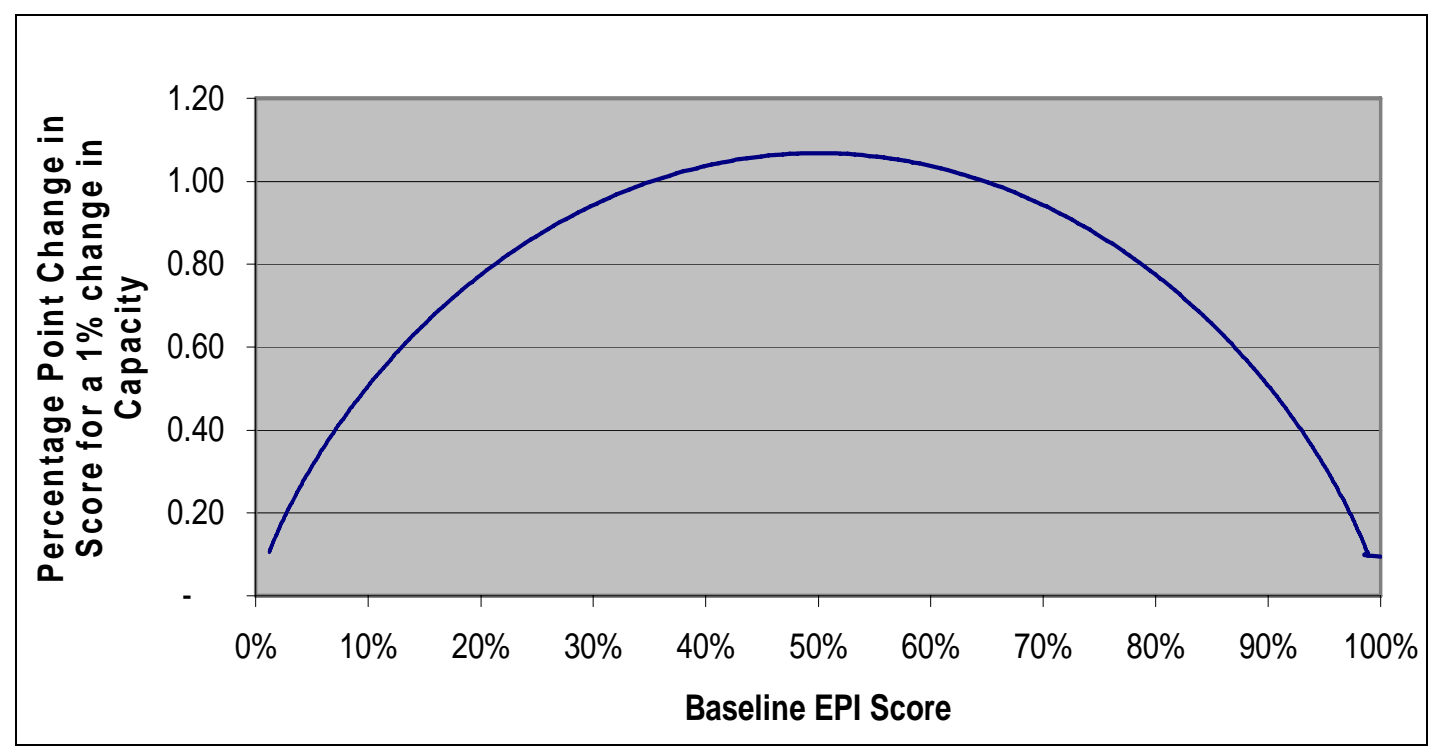

FIGURE 4 Response of the EPI Score to a Change in the Definition of Capacity

\subsection{USE OF THE ENERGY STAR CEMENT EPI}

After three years of work with cement manufacturers, the ENERGY STAR cement EPI is complete, as is a spreadsheet tool for calculating EPI scores. The EPA intends to use this EPI to motivate improvement in energy efficiency in U.S.-based cement manufacturing plants. The EPA, through its ENERGY STAR program that focuses on energy efficiency in cement manufacturing, has been working closely with the companies that make up in this industry to promote strategic energy management. The EPI is an important tool that enables companies to determine how efficiently each plant is using energy and whether better energy performance should be expected.

The EPA recommends that companies use the EPI on a regular basis. At a minimum, it suggests that corporate energy managers benchmark each plant once a year. A more proactive plan would be to use benchmarks for every plant in the company on a quarterly basis. The EPA suggests that the EPI scoring be used to set goals for improving energy efficiency at both the plant and corporate levels.

The model described in this report is based on the performance of the industry for a specific period of time. Since it is likely that overall energy efficiency will change as technology and business practices change, this model will need to be updated. The EPA therefore plans to update the model every few years, contingent on whether newer data are made available by the industry. 


\section{REFERENCES}

EPA (U.S. Environmental Protection Agency), 2003, Guidelines for Energy Management, Washington, DC; http://www.energystar.gov/index.cfm?c=guidelines.guidelines_index.

Greene, W.H., 1993, "The Econometric Approach to Efficiency Analysis," pp. 68-119 in The Measurement of Productive Efficiency: Techniques and Applications, H. Fried et al. (editors), Oxford University Press, NY.

PCA (Portland Cement Association), 1997 and various years, U.S. and Canadian Portland Cement Industry: Plant Information Summary, Skokie, IL.

Worrell, E., and C. Galitsky, 2004, Energy Efficiency Improvement Opportunities for Cement Making: An ENERGY STAR Guide for Energy and Plant Managers, Report LBNL-54036, Lawrence Berkeley National Laboratory, Berkeley, CA, Jan.; http://www.energystar.gov/ ia/business/industry/LBNL-54036.pdf. 



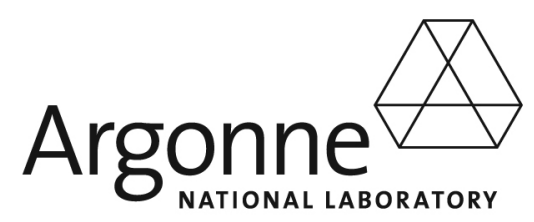

Decision and Information Sciences Division

Argonne National Laboratory

9700 South Cass Avenue, Bldg. 900

Argonne, IL 60439-4832

www.anl.gov

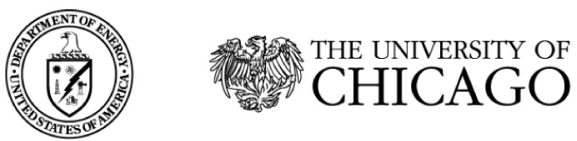

A U.S. Department of Energy laboratory managed by The University of Chicago 